Technological University Dublin ARROW@TU Dublin

\title{
Raman Spectroscopic Mapping for the Analysis of Solar Radiation Induced Skin Damage
}

Hugh Byrne

Technological University Dublin, hugh.byrne@tudublin.ie

Syed Mehmood Ali

Technological University Dublin

Franck Bonnier

Technological University Dublin, Franck.Bonnier@tudublin.ie

See next page for additional authors

Follow this and additional works at: https://arrow.tudublin.ie/radart

\section{Recommended Citation}

Byrne, H., Ali, S. M., Bonnier, F. Ptasinski, K., Lambkin, H., Flynn, K. and Lyng, F. M. Raman spectroscopic mapping for the analysis of solar radiation induced skin damage. Analyst, 138 (14), 3946 - 3956 (2013) doi:10.1039/C3AN36617K

This Article is brought to you for free and open access by the Radiation and Environmental Science Centre at ARROW@TU Dublin. It has been accepted for inclusion in Articles by an authorized administrator of ARROW@TU Dublin. For more information, please contact arrow.admin@tudublin.ie, aisling.coyne@tudublin.ie, gerard.connolly@tudublin.ie.

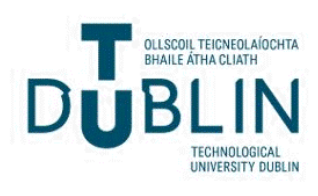




\section{Authors}

Hugh Byrne, Syed Mehmood Ali, Franck Bonnier, K. Ptasinski, Helen Lambkin, Kathleen Flynn, and Fiona Lyng

This article is available at ARROW@TU Dublin: https://arrow.tudublin.ie/radart/38 


\title{
Raman Spectroscopic mapping for the analysis of solar radiation induced skin damage
}

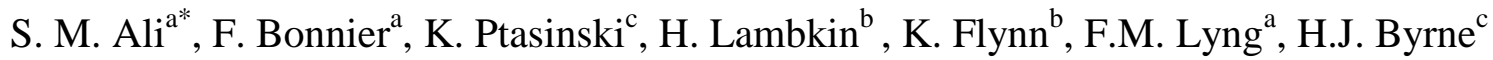 \\ ${ }^{a}$ Radiation and Environmental Science Centre, Focas Research Institute, Dublin Institute of Technology, Kevin Street, Dublin 8, \\ Ireland. \\ ${ }^{\mathrm{b}}$ School of Biological Sciences, Dublin Institute of Technology, Kevin Street, Dublin 8, Ireland. \\ ${ }^{\mathrm{c}}$ Focas Research Institute, Dublin Institute of Technology, Kevin Street, Dublin 8, Ireland.
}

*Corresponding Author: Syed Mehmood Ali,

Radiation and Environmental Science Centre

Focas Research Institute, Dublin Institute of Technology,

Kevin Street, Dublin 8, Ireland.

E mail address: mehmood.ali@dit.ie

Ph: +35314027966

\begin{abstract}
The effects of simulated solar irradiation of an artificial skin model have been examined using Raman spectroscopy and the results are compared with cytotoxicological and histological profiling. Samples exposed for times varying between 30 minutes and 240 minutes were incubated post exposure for a period of 96hours. The cytotoxicological response as measured by
\end{abstract}


the MTT [3-(4,5-dimethylthiazol-2-yl)-2,5- diphenyl tetrazolium bromide] assay demonstrated a $\sim 50 \%$ loss of viability of the artificial tissue after 120 minutes exposure. Histological staining of tissue sections showed considerable loss of cellular content in the epidermal layer at this endpoint. Raman spectroscopic mapping of tissue sections, coupled with K-means cluster analysis (KMCA) clearly identified the dermal and stratum corneum layers and differentiated further substructures of the epidermis. Post irradiation, a significant loss of DNA features in the basal layer was apparent in the results of the KMCA. Principal Components Analysis (PCA) of layers identified by the KMCA post exposure compared with controls indicated a significant increase in the lipidic signatures of the stratum corneum. In the dermal layer, little photodamage was observed, but a similar increase in lipidic signatures in the basal layer was accompanied by a decrease in DNA and protein contributions. The spectral profiles of the photodamage to the basal layer as identified by PCA are consistent over the exposure periods of 30-240 minutes, but an examination of the evolution of features associated with specific biochemical components indicated DNA damage and loss of lipidic signatures at the early exposure times, whereas changes in protein signatures appeared to evolve over longer periods. In comparison to the cytotoxicological responses, the study demonstrates that Raman spectroscopy can identify biochemical changes as a result of solar exposure at time points significantly earlier than changes in tissue viability are observed.

\section{Keywords}

Raman Spectroscopy, K-means Cluster Analysis, Principal Components Analysis, Human skin models, simulated solar radiation, collagen, lipids, DNA damage, biochemical analysis 


\section{Introduction}

Skin cancer has the highest incidence of all cancers worldwide ${ }^{1}$. Every year, there are more new cases of skin cancer than the combined incidence of cancers of breast, lung and colon ${ }^{2}$. However, if diagnosed at an early stage, the prognosis is quite good, highlighting the demand for improved rapid screening and diagnostic technologies ${ }^{3-5}$. Solar irradiation, as one of the most important environmental stressors, has long been known to be the main etiological cause of skin cancers and accelerated skin ageing. Carcinogenesis happens when the continuous and cumulative exposure to sunlight results in non repairable damage to the DNA and abnormal growth of the skin cells is triggered. It is speculated that around $90 \%$ of skin cancer occurs due to unprotected and repeated exposure to UV radiation from sun ${ }^{6}$, and thus understanding the processes and identifying markers of early stages of DNA damage in skin due to exposure to solar radiation are potentially important in disease diagnosis and prevention strategies.

Currently, cancer diagnosis relies heavily on histopathological examination of the affected tissue, a protocol which is still considered to be the gold standard. However, this process is not only time consuming but also costly. To perform histopathology, biopsies may be analysed using several tools including endoscopy for hollow organs such as the gastrointestinal tract, lungs, bladder, the Papanicolaou (Pap) smear test for the cervix and mammography for breast cancer diagnosis. However, sampling errors can limit the effectiveness of these procedures and may lead to unwanted removal of tissue. Moreover, excisional biopsy of delicate organs associated with the central nervous or vascular systems could be hazardous. An ideal diagnostic test for early disease detection should be rapid and non-invasive ${ }^{3,7}$. 
Vibrational spectroscopy is a means of establishing a fingerprint of a material through the characteristic molecular vibrations. It is a routine technique for fingerprinting and identifying chemicals and acts as a standard method of analytical pharmacy and chemistry ${ }^{8}$. The potential of vibrational spectroscopy for diagnostic applications has been demonstrated, notably in dermal applications ${ }^{9-11}$, as well as for in vitro screening of toxicological effects of ionising radiation ${ }^{12}$, nanoparticles ${ }^{13,14}$ and the action of chemotherapeutic agents ${ }^{15}$. Raman and infrared (IR) spectroscopy additionally provide detailed information of the molecular structure and composition of the tissue, ultimately promising an analysis of disease origin. Thus they offer additional information, potentially valuable for diagnosis, that is not provided by X-ray or MRI techniques ${ }^{16}$. Raman spectroscopy has been demonstrated to have higher spatial and spectral resolution than IR spectroscopy, however ${ }^{17}$. It has been furthermore demonstrated that some of the experimental difficulties associated with the measurement of chemical and physical inhomogeneity can be surmounted ${ }^{18,19}$. However, the study of human skin necessarily involves huge variations related to the origin of the samples ${ }^{17}$. Many parameters can influence the experimental observations and these have to be taken into account. These include considerations such as sex, age, pathologies, smoking habits, diet, and skin colour. All these variables influence the data obtained and make the analysis of the effect of external factors such as UV radiation difficult. It is therefore proposed that, by using 3D skin models, the variations due to these different parameters will be removed such that the underlying, early stage effects of UV radiation, both in terms of cytotoxicological responses and morphological changes, can be established on a molecular level, through the use of Raman spectroscopy, coupled with multivariate data analytical techniques. These models also represent an alternative system for testing transdermal delivery of pharmacological products or skin moisturising and protection 
products, in accordance with the EU Directive (2010/63/EU) to Replace, Reduce and Refine the use of animals for scientific research.

While investigating biological responses to UV irradiation, the use of natural solar radiation would be ideal. However, it would require strict aseptic conditions for cell culture and day to day fluctuations in spectral irradiance from the sun due to weather conditions, time of day, season and geographical location make the use of natural solar radiation near impossible. As an alternative, the use of artificial irradiation sources are the most pragmatic option, since stability and reliability are essential to achieve trustworthy data.

In this work, Raman spectroscopy is employed to explore the biochemical changes in artificial skin sections exposed to varying degrees of the full spectrum of simulated solar radiation. The results are compared to cytotoxicological evaluation of the reduced viability of the tissue model as a result of exposure. The data analysis protocol was in accordance with previous work which demonstrated that K-means means cluster analysis (KMCA) of Raman spatial profiles of unprocessed and formalin fixed paraffin processed (FFPP) skin tissue sections successfully discriminated the structural layers of skin while principal components analysis differentiated the identified clusters based on their dominant characteristic biochemical constituents ${ }^{17}$. Using similar analysis, the spectral profiles of model tissue sections clearly differentiate the superficial, epidermal, and dermal regions, which compare well with the spectral profiles of human skin sections as well as the morphology revealed by histological staining of the sections. Exposure dependent biochemical changes can be localised within the different layers of the skin structure and their biochemical origin elucidated. It is demonstrated that Raman spectroscopy can identify a significant degree of biochemical damage at stages where minimal loss in tissue viability is observed, suggesting the modality holds great potential for early disease diagnosis. 


\section{Materials and Methods}

\section{Preparation of Tissue samples}

MatTek's patented EpiDerm ${ }^{\mathrm{TM}}$ artificial skin model consists of normal, human-derived epidermal keratinocytes (NHEK - Neonatal-foreskin tissue) and normal human-derived dermal fibroblasts (NHDF - Neonatal skin), from a single donor, which have been cultured to form a multilayered, highly differentiated model of human epidermis. These ready to use tissue models are also known generically as reconstructed human epidermis (RhE). Full technical specifications, culturing details and examples of applications are provided online (http://www.mattek.com/pages/products/epidermft/specification). The EpiDerm ${ }^{\mathrm{TM}}$ skin model exhibits in-vivo like morphology and growth characteristics which are uniform and highly reproducible. EpiDerm ${ }^{\mathrm{TM}}$ consists of organized basal, spinous, granular and cornified layers analogous to those found in vivo. EpiDerm ${ }^{\mathrm{TM}}$ is mitotically and metabolically active. The EpiDerm cultures should be treated similarly to normal in vitro cell cultures.

Each standard EpiDerm Full thickness kit (EFT-400) consists of 24 tissues. On delivery, EFT 400 samples were transferred into the $0.9 \mathrm{ml}$ of maintained media (provided by MatTek) and were incubated for 24 hours in $\mathrm{CO}_{2}$ at $37^{\circ} \mathrm{C}$. After the incubation period, the tissue samples were exposed to simulated solar radiation (10 exposed and 10 control). After exposure, all samples were transferred into fresh media and incubated for a further 96 hours, after which they underwent further processing and sectioning, before Cytotoxicological (5 exposed and 5 control), Histological and Spectroscopic (5 exposed and 5 control) analyses, as detailed in the relevant sub sections below.

\section{Biochemical compounds}


For comparison to tissue spectra, a number of biochemical compounds were analysed by Raman spectroscopy. The samples were purchased from Sigma-Aldrich (Ireland). Raman spectra were recorded from lyophilised deoxyribonucleic acid from calf thymus deposited on a $\mathrm{CaF}_{2}$ substrate. Ribonucleic acid from baker's yeast (S.cerevisiae) was first suspended in water and deposited onto $\mathrm{CaF}_{2}$ substrates and dried before recording. Sphingomyelin and L- $\alpha-$ phosphatidylcholine (1,2-Diacyl-sn-glycero-3-phosphocholine, 99\% from egg yolk) were dispersed in chloroform and small amounts of material were drop cast onto $\mathrm{CaF}_{2}$ substrates and left to dry before spectral acquisition.

\section{Dosimetry}

All irradiation experiments in this study were performed using an Oriel solar simulator (Abet Technologies, Sun 2000 solar simulator), which provides irradiation over the entire simulated solar spectrum including the UVA and UVB regions. The Oriel solar simulator was calibrated using spectroradiometry as described in detail in ${ }^{16}$. As an indication of dose, integrating the spectral distribution from $280-400 \mathrm{~nm}$ yielded a total UV intensity of $54.88 \mathrm{Wm}^{-2}, 52.7 \mathrm{Wm}^{-2}$ in the UVA (315-400 nm) and $2.18 \mathrm{Wm}^{-2}$ in the UVB $(280-315 \mathrm{~nm})$ region. In the experimental section, exposures are presented in terms of exposure time, noting that $1 \mathrm{~W} \mathrm{~m}^{-2}$ equals $1 \mathrm{Jm}^{-2} \mathrm{~s}^{-1}$. Thus, for example, a $30 \mathrm{~min}(1800 \mathrm{sec})$ exposure at an intensity of $54.88 \mathrm{Wm}^{-2}\left(54.88 \mathrm{Jm}^{-2} \mathrm{~s}^{-1}\right)$ provides a dose of $98,784(54.88 \times 1800) \mathrm{Jm}^{-2}$ or $9.8784 \mathrm{Jcm}^{-2}$. For comparison, a dose level of $\sim 50 \mathrm{Wm}^{-2}$, corresponds to the combined UVA and UVB levels of solar radiation in Albuquerque, $\mathrm{USA}^{20}$.

\section{Solar exposure}


In previous studies ${ }^{20}$, cell death as a result of solar irradiation was found to be primarily mediated through the formation of reactive oxygen species (ROS) via riboflavin photosensitisation and degradation in the cell culture medium. The presence of phenol red in the medium was found to significantly reduce the toxicity of riboflavin, however. Exposure in riboflavin-free medium resulted in significantly increased cell survival compared to identical exposure in riboflavin containing medium ${ }^{21}$. It is important therefore to expose in riboflavin free medium. It is also important that the samples are exposed to the full simulated solar spectrum, and thus irradiation was performed without the plastic lids of the sample containers. For solar irradiation, 20 tissue samples were transferred to a riboflavin free medium $(0.3 \mathrm{ml}$ per well). 10 samples were used for irradiation exposure and 10 served as sham-irradiated control. The control plates are treated in the same way as the irradiated tissues, with the exception of the period of exposure to radiation, during which they were kept at room temperature. After startup, the solar irradiator was allowed to stabilise for a minimum of 15 minutes. Immediately before each irradiation, the exposure field of the Oriel solar simulator was sterilised using $99 \%$ methanol methylated spirit, to minimise any contamination of the exposed cultures. Tissues were irradiated for 30, 90, 120, 180 and 240 minutes which equate to doses of 20,30, 40, 60 and $80 \mathrm{~J} / \mathrm{cm}^{-2}$, respectively. Post exposure, the tissues were removed from the exposure field, the riboflavin-free medium was changed to the MatTek growth medium and tissues were returned to the incubator for 96 hours at $37^{\circ} \mathrm{C}, 5 \% \mathrm{CO}_{2}$. After 96 hours post exposure incubation, 5 tissue samples were used for cytotoxicity assessment and 5 were used for Raman spectroscopy. In the case of the control samples, 5 were employed for cytotoxicity assessment and 5 were used as controls for Raman spectroscopy. 


\section{Cytotoxicity assay}

The MTT assay is recommended by MatTek for in vitro toxicology testing and the protocol used here has been adapted from that provided (http://www.mattek.com/pages/in-vitro-toxicology/). Although the MTT assay is limited in the mechanistic information it yields, the primary function of its use for this study is to validate the tissue irradiation protocol, by verifying exposure levels and times induced significant cell death.

MTT [3-(4,5-dimethylthiazol-2-yl)-2,5- diphenyl tetrazolium bromide] was obtained from MatTek corporation. The MTT assay was performed according to a method reported previously 22, 23. MTT is a yellow coloured molecule that is converted to its purple formazan form by mitochondrial reductases in living cells, and thus measurement of its absorbance is indicative of the level of cellular metabolic activity and changes in cell viability due to exposure to solar radiation. A 96 hours post exposure period was chosen along with the wide range of exposure times, as this provided a wide range degree of cytotoxicity with which to challenge the predicative ability of the Raman spectral measurement.

The MTT assay (MTT-400, MatTek Corporation) was carried out as per manufacturer's instructions. A total of 10 samples were used in the MTT tissue viability assay. In brief, at the end of 96 hours post exposure, EFT-400 tissue samples were washed thrice with PBS and placed in fresh 6 well plates containing $2.0 \mathrm{ml} /$ well of the MTT solution. The MTT solution was introduced directly beneath the insert membrane so that the solution is in contact with it. After 3 hours of incubation at $37^{\circ} \mathrm{C}, 5 \% \mathrm{CO}_{2}$, viable tissues will convert the MTT to a purple dye. The amount of conversion is proportional to the viability of the tissue. Just prior to the end of 3 hours incubation, $3.0 \mathrm{ml}$ of MTT extractant solution were dispensed into the 6 wells plates. Each insert was removed carefully; the bottom was blotted with a paper towel and the inserts were 
transferred into fresh 6-well plates containing the MTT extractant solution. An additional $1.0 \mathrm{ml}$ of extractant solution was dispensed to the apical surface of each tissue. The extractant solution with cluster inserts were shaken for 2 hours $\left(\mathrm{IKA}^{(\mathrm{R})} \mathrm{KS} 130\right.$ B basic). During this period, the plate was protected from light exposure and sealed to prevent extractant evaporation. After 2 hours extraction, inserts were discarded and the contents of each well were mixed thoroughly before transferring $200 \mu \mathrm{l}$ of each sample into 96-well plates. The optical density of the samples was read at $570 \mathrm{~nm}$ using a micro-plate reader (Tecan Genios, Grodig, Austria).

\section{Histology}

Hematoxylin and Eosin staining was initially performed to analyse the general morphology of the unexposed and exposed artificial skin tissues. Eosin is a contrast stain that allows for a general visualization of tissue morphology, staining the fibrous collagen of the dermis pink, and the stratum corneum dark red. Hematoxylin is a purple stain which allows visualisation of cellular nuclei. The artificial tissue sections were formalin fixed, paraffin embedded, and routinely processed ${ }^{17}$. Sections of thickness $8 \mu \mathrm{m}$ were stained with H\&E. Artificial tissue sections were stained in Haematoxylin for 5 minutes and subsequently washed in running water for 3 minutes. Excess staining was removed by repeated dipping of the sections into an acid alcohol mixture that consisted of $1 \%$ hydrochloric acid and $70 \%$ ethanol. Tissues were again washed in running water for 1-2 sec and were slowly dipped in 1\% Eosin for 3 minutes. Tissues were washed well in tap water, excess Eosin was removed and the sections were dehydrated in xylene and mounted on glass slides with DPX resin and a coverslip.

\section{Raman Spectroscopy}


A Horiba Jobin-Yvon LabRAM HR800 spectrometer with an external $300 \mathrm{~mW}$ diode laser operating at $785 \mathrm{~nm}$ as source was used throughout this work. For the measurements, either a x100 objective (MPlanN, Olympus) or a x100 immersion objective (LUMPlanF1, Olympus) was employed, each providing a spatial resolution of $\sim 1 \mu \mathrm{m}$ at the sample. The confocal hole was set at $100 \mu \mathrm{m}$ for all measurements, the specified setting for confocal operation. The system was spectrally calibrated to the $520.7 \mathrm{~cm}^{-1}$ spectral line of silicon and the intensity response function was corrected using the Standard Reference Material (SRM) No. 2243 of the National Institute of Standards, Boulder, Colorado, USA (NIST SRM 2243, 2242, 2241) ${ }^{2}$. The Labram system is a confocal spectrometer that contains two interchangeable gratings (300 and 900 lines $/ \mathrm{mm}$ respectively). In the following experiments, the 300 lines $/ \mathrm{mm}$ grating was used, giving a spectral dispersion of $\sim 1.5 \mathrm{~cm}^{-1}$ per pixel. The detector used was a 16-bit dynamic range Peltier cooled CCD detector. A step size of $2 \mu \mathrm{m}$ was employed for tissue mapping.

For Raman spectroscopic analysis, tissue cross sections of $20 \mu \mathrm{m}$ thickness were cut with a cryomicrotome (Leica CM $1850 \mathrm{UV}$ ) and were stored at $-20^{\circ} \mathrm{C}$ until used. Measurement of Raman spectra in water immersion has been demonstrated to significantly reduce the spectral background ${ }^{14}$ as well as any photodegradation ${ }^{15}$ and thus artificial tissue samples were measured under water immersion using the immersion objective (LUMPlanF1, Olympus). All individual biochemical compounds were recorded in air using the x100 objective (MPlanN, Olympus). Once all spectra were acquired, a background of substrate measured under identical conditions was subtracted. Minimal baseline correction, smoothing and normalization were also performed in order to improve the quality of the acquired spectra.

\section{Data Analysis}


K-means cluster analysis (KMCA) was employed to analyse the spectral variations in tissue. It is one of the simplest unsupervised learning algorithms that solves the well known clustering problem and is often used for spectral image analysis ${ }^{24}$. In general, its is used to group or classify spectra that are similar, therefore forming clusters represented by the spectral mean which identify groups or regions of an image that have the same molecular properties.

Before the classification of the data set is initiated, the number of clusters (k) has to be determined by the operator. In line with previous analyses of human skin tissue sections ${ }^{17}$, five was chosen as the number of clusters for analysis of the artificial skin sections. KMCA maps were calculated several times to make sure a stable solution was reached. The percentage of convergence was set to $99.9 \%$ and the number of clusters was set to 5 . The cluster-membership information was then plotted as a pseudo-color map by assigning a color to each different cluster.

As KMCA groups and represents similar spectra by their mean, principal components analysis (PCA) was employed to further analyse the grouped spectra and compare them with unexposed controls. PCA is a multivariate analysis technique that is widely used to simplify a complex data set of multiple dimensions ${ }^{25}$. It allows the reduction of the number of variables in a multidimensional dataset, although it retains most of the variation within the dataset. The other advantage of this method is the derivation of loading which represent the variance of each variable (wavenumber) for a given PC. Analysis of the loading of a PC can give information about the source of the variability inside a dataset, derived from variations in the chemical components contributing to the spectra. In this work, it is used to highlight the biochemical changes in the different layers of the skin model as a result of irradiation.

\section{Results}


The MTT assay is a measure of the mitochondrial metabolic activity and in the current study is used as a standard against which to map the cytotoxicity induced as a result of exposure to simulated solar radiation. The cytotoxicity was observed to increase over the period of 96 hours post exposure and thus this time period was employed for all measurements. The cytotoxicity induced in skin models after this post exposure time, as determined by the MTT assay, due to the exposure to solar radiation for variable time periods, is shown in Figure 1. The level of viability in each sample was normalised to that of the control sample cultured over the same time period. Due to the action of the solar radiation, the mitochondrial activity decreases monotonically, which in turn leads to a decrease in cell viability. A solar irradiation dose over 180 minutes results in a decrease of at least $50 \%$ in cell viability. A further significant decrease in cell viability was observed due to 240 minutes exposure.

Figure 2 shows a microscopic examination of the H\&E stained control tissue sections cultured for 30, 120 and 240 minutes (A,B and C), and 96 hours after exposure to simulated solar irradiation for 30, 120 and 240 minutes (D, E and F). The H\&E staining allows the differentation between the different skin layers (the stratum corneum at the top, dermis at the bottom, seperated by the skin epidermis) as shown in figure 2 (A, B and C). The nuclei in the stratum basal layer reacts to the Hematoxylin dye and are stained blue, while the collagen fibers in the dermis react to the eosin dye and are stained pink, and the stratum corneum is stained dark red.

The H\&E stained images of the control samples of 30, 120, and 240 minutes show different skin layers, stratum corneum at the top and dermis at the bottom separated by the intermediate epidermis. Notably, the level of staining of the nuclei in the stratum basale is quite consistent over time. The main changes are in the thickness of the stratum corneum, although this can be influenced by damage during cutting. 
The H\&E stained images of exposed samples of 30, 120 and 240 minutes show a similar differentation between skin layers (stratum corneum at top and dermis at the bottom seperated by the skin epidermis). Notably, however, the integrity of the blue stained nuceli, characteristic of the basal layer of the epidermis, is compromised with increasing exposure time. This is a clear manifestation of the cytotoxic effect of the simulated solar radiation, indicated by the MTT assay. However, the biochemical origins of this photodamage, and any to the other skin layers are not elucidated by either technique.

\section{Raman Analysis}

Raman and IR spectroscopy coupled with KMCA can be used for the identification of different structures and classification of tumoral regions in tissue sections ${ }^{26,27}$. It may therefore be anticipated that distinct biochemical regions within the skin section can be identified. The maximum biochemical information is contained within the so-called fingerprint region of the spectrum $\left(400-1800 \mathrm{~cm}^{-1}\right)$ and therefore this region was initially analysed. In an automated spectral map of the tissue sections, the spectra recorded on the edge of the tissue exhibit a high degree of variability due to the transition from the outer layer of tissue to the substrate. The variability between these spectra can interfere with the clustering analysis, resulting in the creation of distinct clusters. Best visualization and reproducibility of the different structures existing within the tissue was achieved by setting the number of clusters to 5 . In this way, the variability in the spectra obtained at the edge of the tissue is contained in distinct clusters and does not interfere with the identification of different structures present in the tissue. The spectra were assigned to the 5 different groups according to their similarities and a colour attributed to each cluster. False colour maps were constructed representing the partition of the different clusters in the tissue. 
The structure of the EpiDerm skin model is similar to natural skin. Notably, it does not contain a melanin rich basal layer, which presents the advantage that its fluorescence will not interfere with the Raman spectra, and the pure Raman profile of the epidermis can be revealed. The comparison between the H\&E stainned image of the tissue section (Figure 2A) and the KMCA of the Raman map in figure (3B), suggests that Raman spectroscopy is able to differentiate the artifical tissue section mainly into four layers.

A detailed analysis of the Raman spectroscopy of unprocessed and processed human skin tissue sections has recently been presented ${ }^{17}$. The spectroscopic analysis clearly differentiates three different regions, the epidermis at the top, the dermis at the bottom, seperated by the basal layer of the epidermis. The stratrum corneum of the human skin is characterised by strong features of the keratin and lipids. The intermediate layer is dominated by fluorescence from melanin, identifying it with the basal and malpighian layers, while the dermal layer is identifiable from the dominant contribution of collagen ${ }^{17}$.

Figure 3C presents the mean spectra of the four distinct clusters of the skin model, which show the clear biochemical differences between the different skin model layers. The Raman spectrum in figure 3C (iv) consists almost completely of collagen features and it is therefore identified as the dermis. Assignments of most Raman bands of collagen have been made by Frushour and Koenig ${ }^{28}$. Specific features in the collagen spectrum are two intense bands at $\sim 855 \mathrm{~cm}^{-1}$ and $\sim 938 \mathrm{~cm}^{-1}$. These bands originate from the amino acid side chain vibrations of proline and hydroproline as well as from a $\mathrm{C}-\mathrm{C}$ stretching vibration of the collagen backbone. Proline and hydroxyproline make up about one-fourth of the amino acids in collagen, a higher proportion than in most other proteins ${ }^{29}$. 
The uppermost layer is identified as the stratum corneum of human skin as the cluster spectrum in figure 3C(i) is mainly composed of features of keratin and lipids. The position of the amide I band at $1655 \mathrm{~cm}^{-1}$ indicates that keratin in the human stratum corneum adopts predominantly an $\alpha$-helical conformation ${ }^{30,31}$. The contributions of lipids are normally observed at $1061 \mathrm{~cm}^{-1}, 1128$ $\mathrm{cm}^{-1}$ and $1296 \mathrm{~cm}^{-1} 24$.

Between the stratum corneum and dermis, some substructure of the epidermal layer is identified. The stratum basale or germinativum is the deepest layer of the epidermis, and is primarily composed of keratinocytes separated from the dermis by a continuous basal membrane. The spectrum of the basal layer in figure 3C (iii) contains specific bands which are characteristic of DNA. The bands of the DNA at $788 \mathrm{~cm}^{-1}$ (O-P-O), $813 \mathrm{~cm}^{-1}$ (O-P-O), $1086 \mathrm{~cm}^{-1}$ (O-P-O), 1254 $\mathrm{cm}^{-1}$ (guanine, cytosine), $1320 \mathrm{~cm}^{-1}$ (DNA) and $1340 \mathrm{~cm}^{-1}$ (DNA) are indicative of cellular structures of the skin.

The keratinocoytes of the basal layer migrate towards the surface of the skin. In the process of the differentiation, they progress through the stratum spinosum to the stratum granulosum layer. As a natural process of maturation, the cells flatten and lose their nucleus and the stratum granulosum layer is made up of flattened anuclear cells filled with keratohyalin granules. The KMCA spectrum of Figure 3C(ii) does not show the characteristic DNA bands identifiable in the basal layer and is therefore associated with the stratum granulosum. The keratinocytes in this layer stop dividing and make large amounts of keratin. Finally, the keratinocytes reach the last stage of their maturation and abruptly transform into the flat, fully keratinized, anuclear cells and are described non-viable cornified cells called corneocytes. The differentiated KMCA clusters of Figure 3C are therefore consistent with the transition from the DNA rich stratum basale and the DNA deficient stratum spinosum and granulosum layers, while the uppermost layer of Figure 3C 
(i) is associated with the stratum corneum. Thus, the results presented demonstrate that Raman spectroscopic microscopy can clearly spatially differentiate the different layers of the skin model structure, and clearly identify the biochemical characteristics and the evolution of the cellular structure from the basal layer to the stratum corneum. Notably, the differentiation of the sublayers of the epidermis is possible in the absence of melanin in the skin model.

Figure 4A shows an optical image of a model tissue section of $20 \mu \mathrm{m}$ thickness after 240 minutes exposure to simulated solar irradiation. In the KMCA map of the Raman spectral profiles, shown in figure $4 \mathrm{~B}$, four distinct layers are again differentiated. As before, these correspond to the dermis at the bottom and the stratum corneum at the top, separated by the basal and stratum granulosum layers. Figure 4C presents the different selected cluster mean spectra of the exposed artifical skin tissue, which show the clear biochemical differences between the different layers. Comparing the spectrum of the exposed basal layer in Figure 4C (iii) to that of the unexposed basal layer in Figure 3C (iii), the characteristic bands of the DNA at $788 \mathrm{~cm}^{-1}(\mathrm{O}-\mathrm{P}-\mathrm{O}), 813 \mathrm{~cm}^{-1}$ (O-P-O), $1086 \mathrm{~cm}^{-1}$ (O-P-O), $1254 \mathrm{~cm}^{-1}$ (guanine, cytosine), $1320 \mathrm{~cm}^{-1}$ (DNA) and $1340 \mathrm{~cm}^{-1}$ (DNA) are absent in the exposed sample, indicating radiation induced damage to DNA in the basal layer. The spectrum of the stratum granulosum layer of the human skin is represented in figure $4 \mathrm{C}$ (ii). Notably, the spectra of the stratum basale layer and stratum granulosum, shown as Figure 4C (ii) and 4C (iii), respectively, are no longer differentiated by the loss of spectral features associated with nucleic acids in the upper layer, as compared to the unexposed artifical tissue section in figure $3 \mathrm{C}$ (ii) and iii) resspectively. The layer structure is therefore no longer consistent with the evolution of the keratinocytes as they progess towards the stratum corneum.

Changes to the mean spectra in the basal layer of the epidermis can be identified in the mean spectra of the KMCA analysis. However, these changes in individual spectral features are small 
and changes to the DNA profile of the basal layer may be predicted from the cytotoxicological and histological analysis. No dramatic changes can be seen in the mean spectral profiles of the dermis or stratum corneum. To illustrate the true potential of Raman spectroscopy in elucidating the biochemical changes induced by solar radiation, PCA was employed to further analyse the grouped spectra and compare them with unexposed controls.

Figure $5 \mathrm{~A}$ is a scatter plot of the PCA of spectra associated with K-means cluster 4 of the unexposed tissue section and cluster 2 of the tissue section exposed for 240 minutes, each representing the stratum corneum of the artificial skin section. For visualisation purposes, data associated with the exposed section are coloured blue, while those from the unexposed section are coloured red. Although some dispersion of the clusters is apparent, due to point to point intrasample variability which may to some extent from the tissue processing effects, significant differentiation between the two clusters according to PC1 is observed. PC1 accounts for $65 \%$ of the variance and, as shown in the loading plot of Figure $5 \mathrm{~B}$, it is dominated by negative contributions of spectral features at $\left(1653 \mathrm{~cm}^{-1}, 1440 \mathrm{~cm}-1,1296 \mathrm{~cm}^{-1}, 1129 \mathrm{~cm}^{-1}\right.$ and $1062 \mathrm{~cm}^{-}$ $\left.{ }^{1}\right)$. These features correlate well with those of L- $\alpha$ - phosphatidylcholine and ceramide as shown in figure 5 ( $\mathrm{i}$ and ii). Differentiation of the unexposed artificial tissue section and exposed artificial tissue section for 240 minutes is therefore based on increased lipidic content of the stratum corneum.

A similar PCA analysis of the exposed and unexposed dermis shows no differentiation according to $\mathrm{PC} 1$, which represents $57 \%$ of the variance, as shown in Figure 6A. The features of the loading match well with those of the Raman spectrum of collagen (not shown), indicating that the biggest variance in the spectra of the dermis of both unexposed and exposed samples is due to point to point variations in tissue density and/or morphology. The dermal regions of the 
exposed and unexposed samples are differentiated by PC2, although it accounts for only $15 \%$ of the variance. As shown in figure 6B, PC2 exhibits features which can be associated with lipidic constituents. Their negative loading is indicative of a decrease in lipidic content of the dermis after exposure.

Figure 7A is a scatter plot of the PCA of spectra associated with clusters 2 of the KMCA of the unexposed tissue section and cluster 3 of the tissue section exposed for 240 minutes, each representing the basal layer of the skin. Again, for visualisation purposes, data associated with the exposed section are coloured blue, while those from the unexposed section are coloured red. Clear differentiation between the two clusters according to PC1 is apparent. PC1 accounts for $56 \%$ of the variance and, as shown in the loading plot of Figure $7 \mathrm{~B}$, it is dominated by positive contribution of DNA, collagen and RNA, whose spectra are shown in figure 7B (i, ii and iii). Nucleic acid peaks include those at $\left(599 \mathrm{~cm}^{-1}, 681 \mathrm{~cm}^{-1}, 729 \mathrm{~cm}^{-1}, 788 \mathrm{~cm}^{-1}, 813 \mathrm{~cm}^{-1}, 1096 \mathrm{~cm}^{-}\right.$ $\left.{ }^{1}, 1379 \mathrm{~cm}^{-1}, 1490 \mathrm{~cm}^{-1}, 1507 \mathrm{~cm}^{-1}, 1576 \mathrm{~cm}^{-1}\right)$, while protein peaks appear at $\left(858 \mathrm{~cm}^{-1}, 873 \mathrm{~cm}^{-}\right.$ 1, $\left.\left.920 \mathrm{~cm}^{-1}, 939 \mathrm{~cm}^{-1}, 1243 \mathrm{~cm}^{-1}\right)\right)$. The negative contributions correlate well with spectral features of lipids such as L- $\alpha$ - phosphatidylcholine, (Figure $6 \mathrm{~B}(\mathrm{v})$ ) and also Sphingomyelin (Figure 7B(vi)) at $\left(1064 \mathrm{~cm}^{-1}, 1129 \mathrm{~cm}^{-1}, 1302 \mathrm{~cm}^{-1}, 1142 \mathrm{~cm}^{-1}, 1653 \mathrm{~cm}^{-1}\right)$. The respective positive loadings for the unexposed tissue and negative loadings for the exposed tissue in the scores plot of (Figure 7A), are therefore indicative of a decrease in nucleic acid content in the basal layer of the tissue section, and an increase in lipidic content, as a result of radiation exposure.

A similar PCA analysis was performed on the spectral profiles of the basal layer, in comparison to that of their unexposed controls, for all exposure times. In all cases, the loading of PC1 obtained from the PCA is responsible for the discrimination between the unexposed to exposed 
skin models of the basal layers. As shown in figure 8, the PC1 loading for the different exposure times show strong similarities, illustrating the consistencies of the responses.

The peak intensities of the PC1 loadings can be monitored as a function of exposure time. Figure 9 shows the example of the evolution of the peaks of PC1 at $813 \mathrm{~cm}^{-1}$, associated with O-P-O of DNA, at $858 \mathrm{~cm}^{-1}$, associated with the C-C vibration of proteins and at $1653 \mathrm{~cm}^{-1}$, associated with the $\mathrm{C}=\mathrm{O}$ stretched of lipids. The evolution of the respective spectral changes indicates that both DNA damage and changes in lipidic content occur at the early stages of exposure, potentially as a direct effect of the irradiation, whereas changes in protein features appear to evolve at a later stage, potentially as an indirect physiological result of irradiation. A similar temporal evolution is shown for other PC peak loadings associated with the respective biochemical components. Remarkably, although the cytotoxicity analysis indicated only an $\sim 15 \%$ reduction in viability after 30minutes exposure, the apparent changes in the Raman peaks corresponding to the DNA and lipids in the basal layers exposed to solar radiation have reached $\sim 50 \%$ of what appears to be a saturated value after 240 minutes exposure.

\section{Discussion}

Skin cancer is the most common form of malignancy in the Caucasian population ${ }^{32}$ and it is well established that its initiation is associated with over-exposure to ultra violet radiation ${ }^{33}$. Solar UV radiation is implicated in the induction of both malignant melanomas and non-melanoma skin cancer ${ }^{34,35}$. Solar UV radiation is also known to induce cellular and genomic toxicity, reactive oxygen species (ROS) formation, DNA damage, sunburnt cells and higher proteolytic rates ${ }^{36-43}$. If the cellular repair and antioxidant responses to UV radiation are overwhelmed, 
cellular photodamage can occur and may initiate photocarcinogenesis ${ }^{44-46}$. One of the most serious effects of UV is DNA mutagenesis ${ }^{47-49}$. UV absorption by DNA is potentially mutagenic and may lead to the formation of DNA photo-products which are associated with mutagenesis and cancer initiation ${ }^{50}$. Solar radiation-induced DNA strand breaks and protein cross-links are considered to be direct effects, whereas increased mitochondrial damage and/ or dysfunction associated with augmented ROS formation, lipid and protein oxidation and energy depletion are considered to be indirect effects of UV radiation ${ }^{51}$.

Raman spectroscopy identifies the DNA damage associated with cytotoxicity and changes in proteins associated with changes in metabolism. The analysis of the stratum basal layer of the epidermis showed a decrease in Raman peaks corresponding to the DNA and proteins with an increase in Raman peaks corresponding to the lipids. Notably, the changes to the basal layer are clearly evident at the earliest stages of radiation exposure (30minutes), at which point the classical cytotoxicological assay shows only a small decrease in tissue viability. The technique is also considerably more sensitive than the histopathological staining, as it gives a clear indication of the biochemical origin of the photodamage, rather than simply morphological changes in the tissue. The two main types of cell death induced by solar radiation are apoptosis and necrosis ${ }^{52}$. The former involves a cascade of events leading to progressive fragmentation and vacuolization of the cell whereas the latter occurs mostly as a passive process involving cell swelling and disruption of the cell membrane. In addition, while necrosis always affects groups of cells, apoptosis is mostly seen in isolated events ${ }^{52-55}$. Therefore, the measured spectral changes can be used as discriminating signatures for the exposed tissues. Basal cells undergoing apoptosis have been shown to exhibit a relative decrease in the Raman peaks corresponding to DNA and proteins, and an increase in Raman peaks corresponding to lipids ${ }^{56}$ and therefore the solar 
irradiation induced changes to the tissue model observed here are consistent with a specific mechanism of apoptotic cell death.

The epidermis of the human skin is the major reservoir of skin lipids. The lipidic content of human skin consist of phospholipids, ceramide, cholesterol, fatty acid, triglycerides, wax, esters 57, 58. It is well known that the intercellular lipids of the stratum corneum play a crucial role in maintaining the cutaneous barrier function. They also play important roles in human skin function such as cell growth and differentiation, energy storage, protection, signal transduction, hormone production and regulation of gene expression as well as structural components of cells 59. The skin lipids mediate various skin physiological responses such as epidermal barrier homeostasis and epidermal proliferation ${ }^{60,61}$.

It should be noted that the stratum basale layer of the EpiDerm artificial skin model is completely devoid of melanin, and thus the susceptibility to UV radiation damage is considerably higher than real human skin, as evidenced by the significantly changes observed after only 30-60minutes exposure. Indeed, it could be considered as a perfect model of albinism. Nevertheless, the model can serve as excellent demonstration of the potential of Raman spectroscopy to probe the early stages of the skin damage at a molecular level.

The analysis of the stratum corneum of the epidermis showed an increase in Raman peaks corresponding to the lipids. It has previously been demonstrated that irradiation with suberythemal doses of either UVA or UVB yielded an increase in the amount of stratum corneum lipids, especially the ceramide fraction, implying that the increase in the stratum corneum lipids after UVB irradiation is indicative of a local change in the biosynthesis or degradation of these compounds ${ }^{62}$. Moreover, abnormal stratum corneum lipid profiles can be associated with 
defective permeability barrier function in common skin disease like eczema and psoriasis, both of which exhibit hyperproliferation, impaired epidermal differentiation, and barrier dysfunction ${ }^{63}$. Interestingly, in lesional psoriatic skin, the level of glucosylceramide- $\beta$ - glucosidase was seen to be increased compared to non-lesional skin ${ }^{17,63-66}$.

In the stratum corneum of all terrestrial mammals studied to date, the lipid content is comprised of an approximately equimolar mixture of ceramides, free sterols, and fatty acid ${ }^{67,68}$. In a study of intercellular lipids in murine stratum corneum by ${ }^{69}$, it was demonstrated that UVB exposure caused a significant change in trans-epidermal water loss, and that this was associated with a change in the structures of bound and unbound lipids in the stratum corneum. This is consistent with the study of Jiang et al. which, using FTIR in conjunction with Electron Microscopy, demonstrated a disordering of the lipidic structures in the stratum corneum of adult mice after UVB radiation, associated with marked morphological abnormalities in the intercellular lipid domains and lamellar structures. In normal epidermis, the lamellar granules are the sources of the secreted lipids, which eventually organize into stratum corneum intercellular lipid bilayers ${ }^{70,71}$. It has been speculated that acylglucocylceramide exists as a common precursor within lamellar granules for both covalently bound ceramide and acylceramide ${ }^{62}$. UVB irradiation might result in the accumulation of acylglucocylceramide and in a preferential switch toward the biosynthesis of acylceramide, which leads to the increase in acylceramide level, resulting in abnormal ceramide: free sterols: fatty acid ratios and ultimately morphological alterations of the stratum corneum lipidic structures, as the imbalanced lipid mixture may not be completely integrated into a lipid bilayer configuration. In normal epidermis, the lamellar granules at the interface between the stratum corneum and stratum granulosum are the source of the secreted lipids, which eventually organize into stratum corneum intercellular lipid bilayers, and disturbed growth can 
be attributed to the abnormal proliferation of the cellular structures from the stratum basale to the stratum granulosum, as evidenced in the Raman analysis. The role of UV generated reactive oxygen species or other detoxifying agents could also be of importance, and could be probed by irradiation of samples permeated with anti-oxidants such as vitamin E.

The changes to the biochemical profile in the stratum corneum thus do not derive from a direct photochemical effect on the lipidic content ${ }^{72}$, but rather from a change in the physiology of the underlying epithelium. There is little or no flux in the solar spectrum below $4 \mathrm{eV}$, while typical organic bond strengths are of order $5 \mathrm{eV}$. The cellular function can be significantly perturbed by even subtle changes to biomolecular conformation as a result of irradiation, resulting in dramatic changes observed in the cellular content of the basal layer. These proliferate to changes in the lipidic structures of the stratum corneum and are manifest as compromised barrier function, for example. Notably, Raman and infrared spectroscopy are sensitive not only to changes in biomolecular content, as observed in the basal layer, but also to morphological changes in the lipidic structures of the stratum corneum.

In the dermis, little differentiation between exposed and unexposed samples is observed and only slight changes in lipidic signatures are observed. The penetration of the radiation is significantly limited by light scattering, and in human skin the dermis is protected by the melanin content which absorbs strongly across the UV and visible regions. In this context, it is not clear whether any observed changes in the dermal layer of artificial skin models are significant.

\section{Conclusions}


The work presented in this paper demonstrates that Raman spectroscopy, coupled with multivariate statistical techniques, is a powerful tool for the early diagnosis of solar radiation induced cell death in the human skin. This technique can provide information regarding cellular processes and changes in cell biochemistry in human skin models and the interaction of live tissue with external agents such as UV radiation. Effects of radiation exposure are evident at stages where alternative techniques such as cytotoxicological and histopathological techniques show little response and the spectroscopic technique is sensitive to changes in biomolecular morphology as well as more dramatic biochemical content. In general, it is acknowledged that there is a need for novel toxicological screening techniques and assays which can identify sub lethal effects and even contribute to elucidating modes of action ${ }^{73}$. In this context, Raman spectroscopy provides an integrated picture of the response of the cells and tissue to the exogeneous insult of solar radiation. This study demonstrates the feasibility of this technique for the diagnosis of cutaneous pathologies and chemical changes at early stages of damage in human skin. Developments in the techniques of chemometrics and data mining, coupled with parallel established biochemical assays could significantly advance the field.

\section{Acknowledgements}

This research was supported by the National Biophotonics and Imaging Platform (NBIP) Ireland, Higher Education Authority PRTLI (Programme for Research in Third Level Institutions) Cycle 4, co-funded by the Irish Government and the European Union Structural Fund.

\section{Figure Legends:}


Figure 1: Viability of skin models, as determined by MTT absorption, 96 hours after exposure, as a function of exposure time

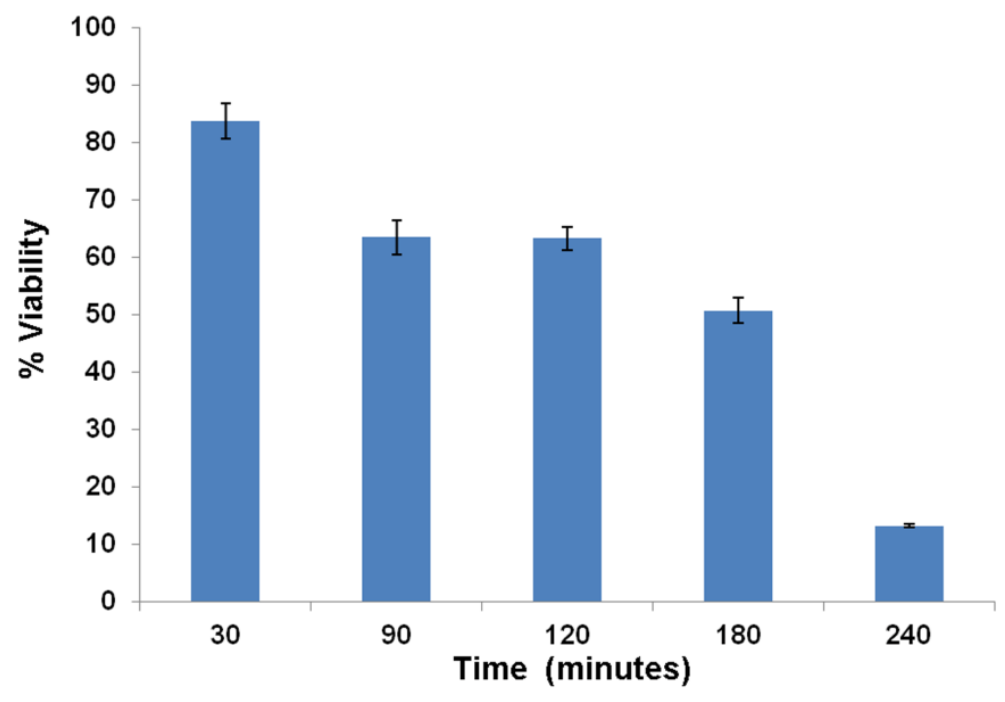

Figure 2: H\&E stained unexposed tissue sections cultured for 30 minutes (A), 120 minutes (B), 240 minutes (C), and 96 hours after exposure for 30 minutes (D), 120 minutes (E) and 240 minutes $(\mathrm{F})$

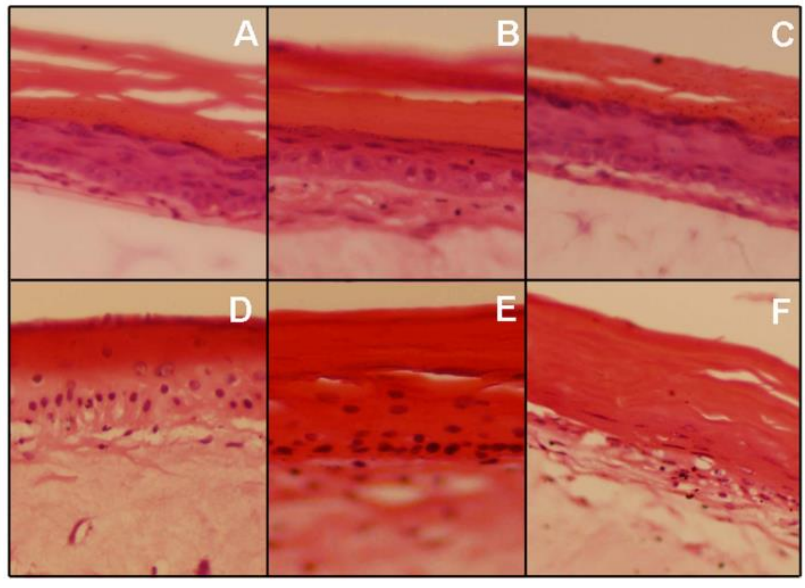


Figure 3: (A) Optical image of unexposed artificial tissue section; (B) KMCA of Raman map of unexposed tissue section (C) KMCA mean Raman spectra of unexposed artificial skin tissue (i) cluster 4, stratum corneum (ii) cluster 3, stratum granulosum (iii) cluster 2, basal layer (iv) cluster 5, dermis.
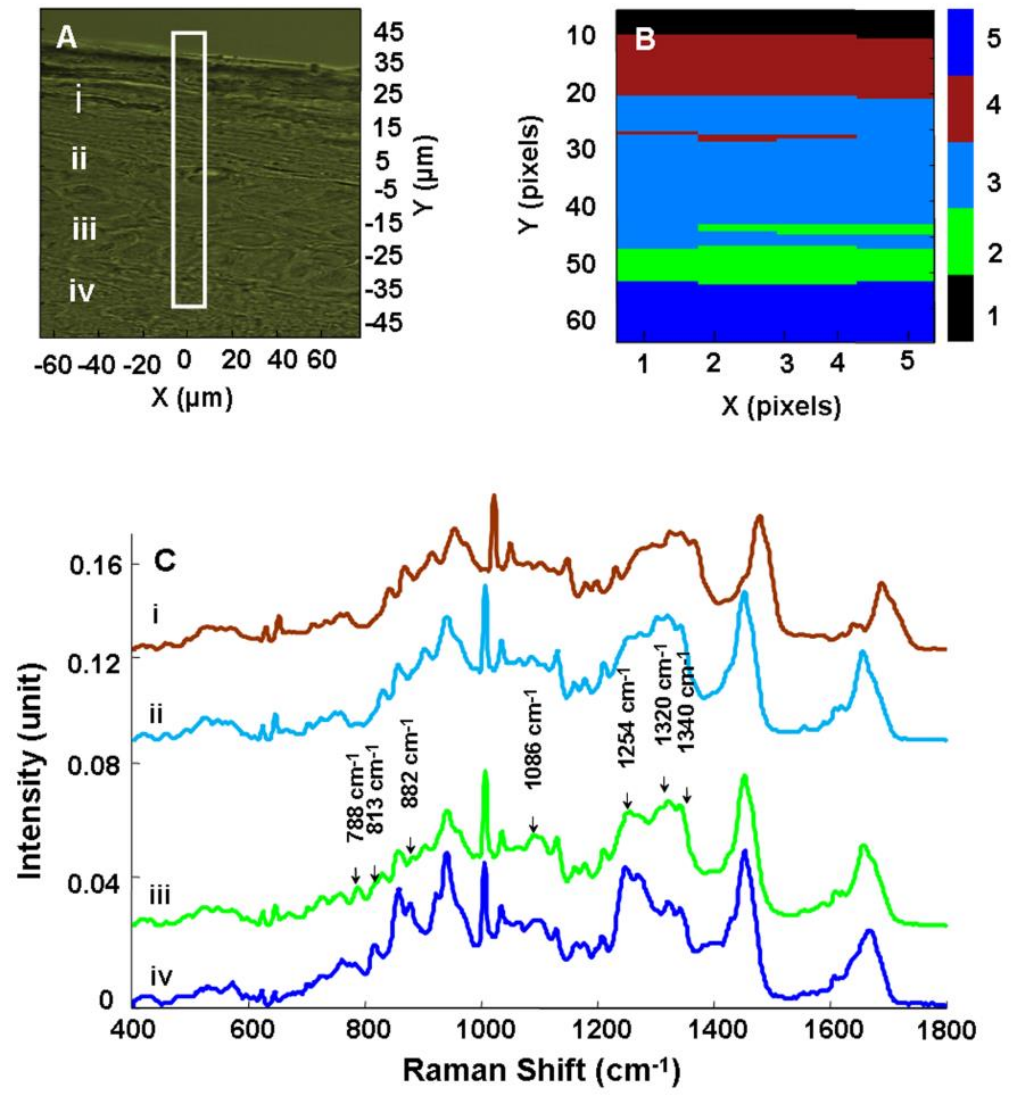
Figure 4: (A) Optical image of 240 minutes exposed artificial tissue section; (B) KMCA of Raman spectral map of 240 minutes exposed; (C) KMCA mean Raman spectra of 240 minutes exposed artificial skin tissue (i) cluster 2, stratum corneum (ii) cluster 1, stratum granulosum (iii) cluster 3, basal layer, (iv) cluster 4, dermis.
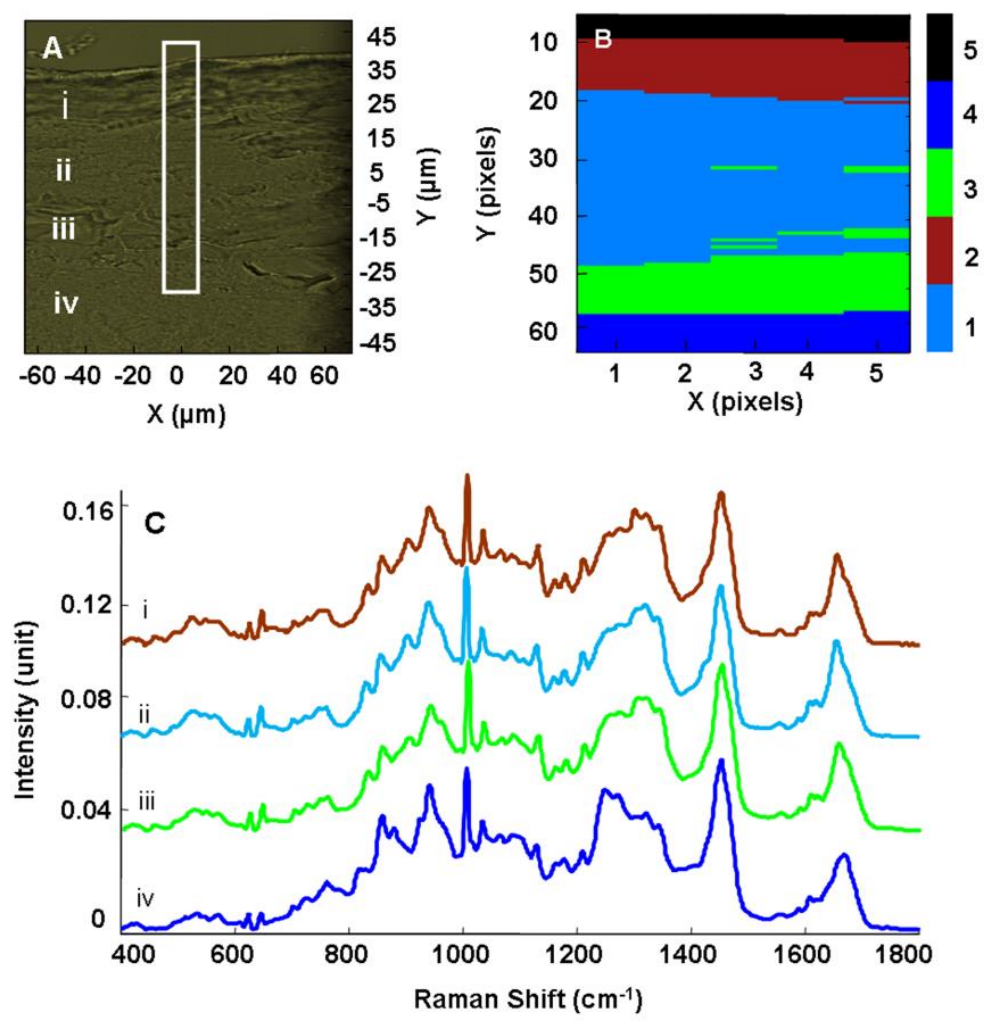
Figure 5: (A): Scatter plot of the PCA of spectra associated with cluster 4 (stratum corneum) of the KMCA of unexposed artificial tissue section (red) and cluster 2 (stratum corneum) of the KMCA of (240 minutes) exposed artificial tissue section (blue). (B): Bottom (i) loading of PC1 compared to Raman spectrum of (ii) L- $\alpha$ - phosphatidylcholine and (iii) Ceramide. The dotted line indicates the zero point in the case of PC1
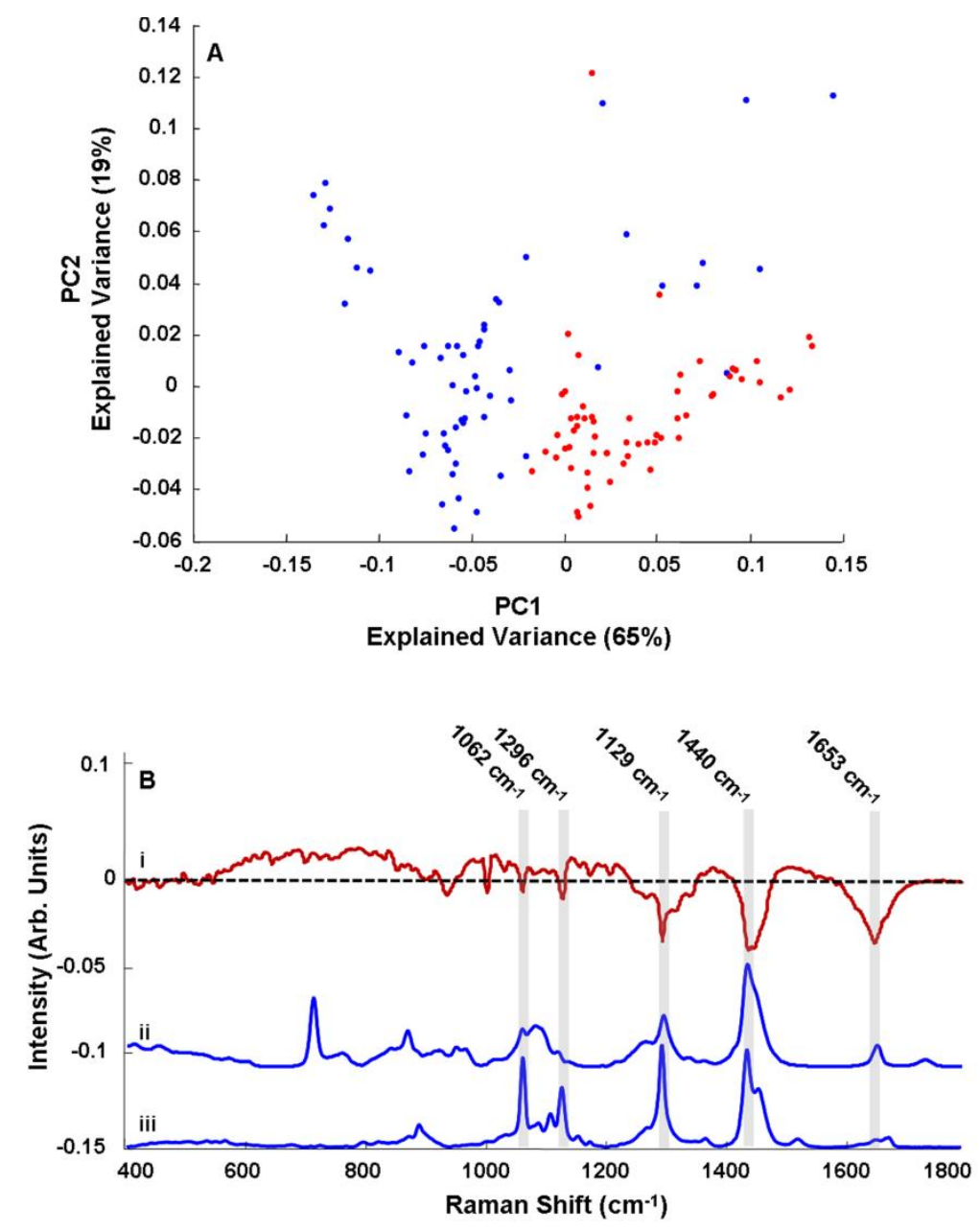
Figure 6: (A) scatter plot of the PCA of spectra associated with cluster 5 (dermis) unexposed artificial tissue sections (red) and cluster 4 (dermis) exposed (240 minutes) artificial tissue section (blue). (B) Bottom: (i) Loading of PC2 compared to the Raman spectrum of (ii) Sphingomyelin and (iii) L- $\alpha$ - phosphatidylcholine
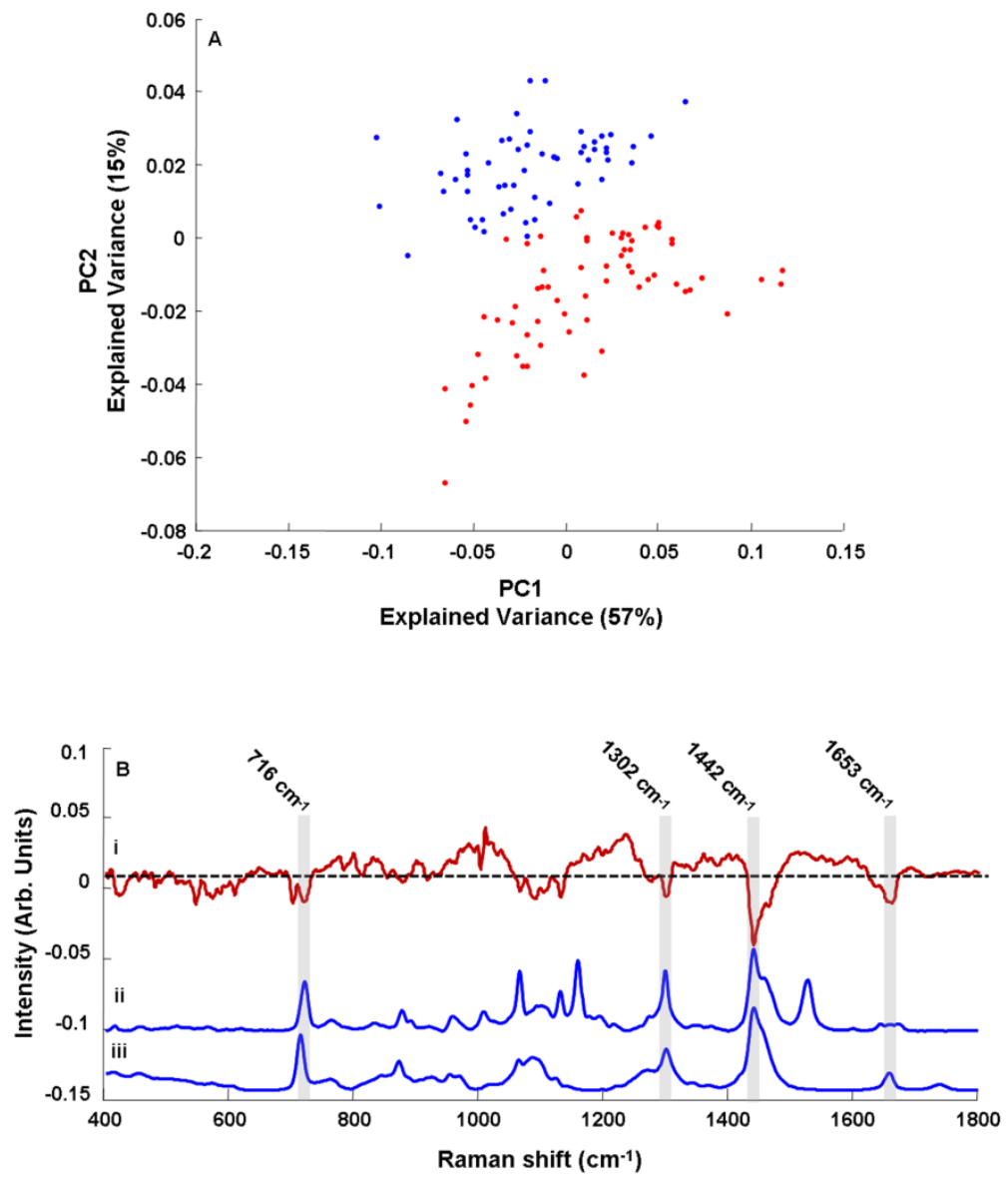
Figure 7: (A): Scatter plot of the PCA of spectra associated with cluster 2 (basal), unexposed artificial tissue sections (red) and cluster 3 (basal), exposed (240 minutes) artificial tissue section (blue). (B): Raman spectra of (i) collagen, (ii) RNA, (iii) DNA, (iv) loading of PC1, Raman spectra of (v) L- $\alpha$ - phosphatidylcholine, and (vi) Raman spectrum of Sphingomyelin. The dotted line indicates the zero point in the case of PC1.
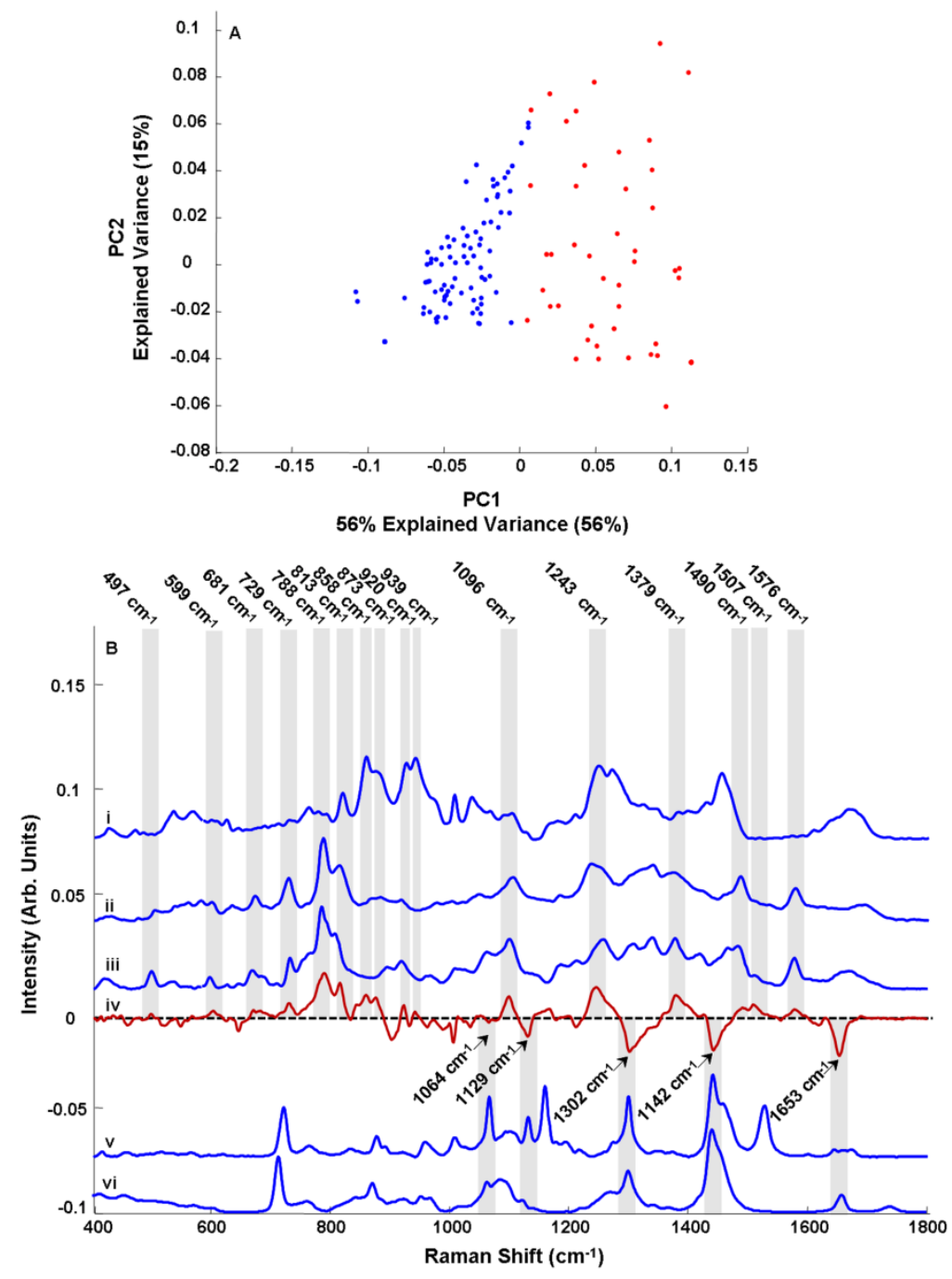
Figure 8: PC1 loadings of the skin models of the basal layers after differing degrees of exposure versus the corresponding control (i) 30 minutes exposure(ii) 90 minutes exposure (iii) 120 minutes exposure (iv) 180 minutes exposure (v) 240 minutes exposure

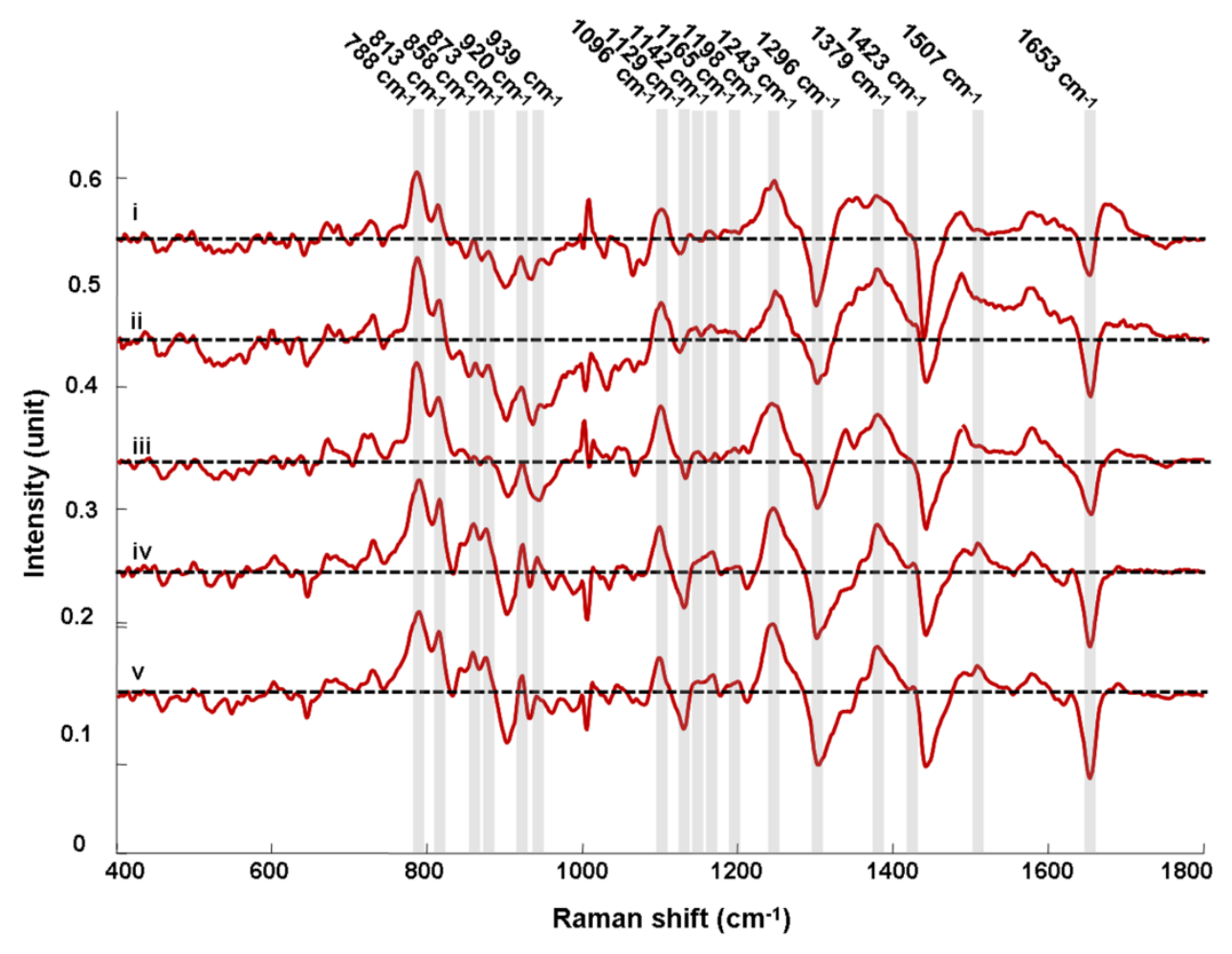


Figure 9: Plot of the PC1 loading of the basal layer (exposed) versus corresponding controls, of the $813 \mathrm{~cm}^{-1}, 1653 \mathrm{~cm}^{-1}$ and $858 \mathrm{~cm}^{-1}$ bands, as representative markers of the DNA, proteins and lipids, showing their dependence on the exposure time.

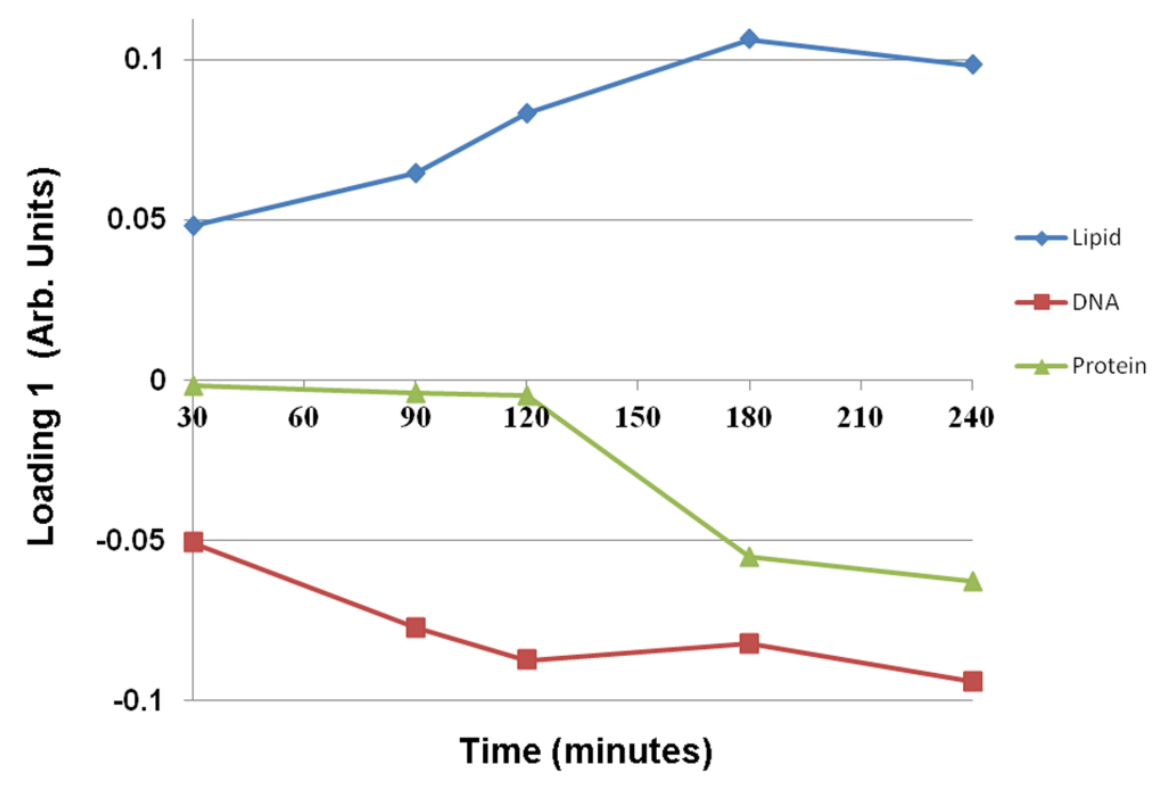




\section{References}

1. Greinert R, Volkmer B, Wende A, Voss S, Breitbart EW, Hautarzt, 2003, 54, 1152-1163.

2. Cancer Facts and Figures, American Cancer Society, Atlanta, 2012.

3. Krishna CM, Sockalingum G, Kegelaer G, Rubin S, Kartha V, Manfait M, Vibrational Spectroscopy, 2005, 38, 95-100.

4. Manoharan R, Wang Y, Feld MS, Spectrochimica Acta Part A, 1996, 52, 215.

5. Mantsch HH, Choo-Smith LP, Shaw RA, Vib. Spectrosc., 2002, 30, 31-41.

6. $\quad$ Armstrong BK, Kricker A, Melanoma Res, 1993, 3, 395-401.

7. Stamey T, Caldwell M, McNeal J, Nolley R, Hemenez M, Downs J, Journal of Urology, 2005, 174, 1155-1156.

8. Wartewig S, Neubert RH, Adv Drug Deliv Rev, 2005, 57, 1144-1170.

9. Caspers P, Lucassen G, Bruining H, Puppels G, Journal of Raman Spectroscopy, 2000, 31, 813-

818.

10. Caspers PJ, Lucassen GW, Carter EA, Bruining HA, Puppels GJ, J Invest Dermatol, 2001, 116, 434-442.

11. Bakker TS, Witjes M, Sterenborg H, Speelman O, Roodenburg J, Marple E, Bruining H, Puppels G, Anal Chem, 2000, 72, 6010-6018.

12. Meade AD, Byrne HJ, Lyng FM, Mutat Res, 2010, 704, 108-114.

13. Dorney J, Bonnier F, Garcia A, Casey A, Chambers G, Byrne HJ, Analyst, 2012, 137, 1111-1119.

14. Knief P, Clarke C, Herzog E, Davoren M, Lyng FM, Meade AD, Byrne HJ, Analyst, 2009, 134, $1182-1191$.

15. Nawaz H, Bonnier F, Knief P, Howe O, Lyng FM, Meade AD, Byrne HJ, Analyst, 2010, 135, 3070-3076.

16. Frank CJ, McCreery RL, Redd DC, Anal Chem, 1995, 67, 777-783.

17. Ali SM, Bonnier F, Tfayli A, Lambkin H, Flynn K, McDonagh V, Healy C, Clive Lee T, Lyng FM, Byrne HJ, J Biomed Opt, 2013, 18, 061202.

18. Bonnier F, Mehmood A, Knief P, Meade AD, Hornebeck W, Lambkin H, Flynn K, McDonagh V, Healy C, Lee TC, Lyng FM, Byrne HJ, Journal of Raman Spectroscopy, 2011, 42, 888-896.

19. Bonnier F, Ali S, Knief P, Lambkin H, Flynn K, McDonagh V, Healy C, Lee T, Lyng F, Byrne H, Vibrational Spectroscopy, 2012, 61, 124-132.

20. Maguire A, Lyng FM, Walsh JE, Radiat Prot Dosimetry, 2010, 140, 147-157.

21. Maguire A, Morrissey B, Walsh JE, Lyng FM, Int J Radiat Biol, 2011, 87, 98-111.

22. Mosmann T, J Immunol Methods, 1983, 65, 55-63.

23. Park B, Cho C, Jang G, Kim K, Park S, J Korean Diabetes Assoc, 2001, 4, 286-296.

24. Krafft C, Codrich D, Pelizzo G, Sergo V, Journal of Biophotonics, 2008, 1, 154-169.

25. Varmuza K. 2009. Introduction to multivariate statistical analysis in chemometrics. New york: CRC Press.

26. Koljenovic S, Schut TCB, van Meerbeeck JP, Maat A, Burgers SA, Zondervan PE, Kros JM, Puppels GJ, Journal of Biomedical Optics, 2004, 9, 1187-1197.

27. Ly E, Piot O, Durlach A, Bernard P, Manfait M, Analyst, 2009, 134, 1208-1214.

28. Frushour BG, Koenig JL, Biopolymers, 1975, 14, 379-391.

29. Caspers PJ, Lucassen GW, Wolthuis R, Bruining HA, Puppels GJ, Biospectroscopy, 1998, 4, S31-S39. 
30. Anigbogu ANC, Williams AC, Barry BW, Edwards HGM, International Journal of Pharmaceutics, 1995, 125, 265-282.

31. Potts RO, Guzek DB, Harris RR, McKie JE, Arch Dermatol Res, 1985, 277, 489-495.

32. Diepgen TL, Mahler V, Br J Dermatol, 2002, 146 Suppl 61, 1-6.

33. Soehnge H, Ouhtit A, Ananthaswamy ON, Front Biosci, 1997, 2, d538-551.

34. Albino AP, Davis BM, Nanus DM, Cancer Res, 1991, 51, 4815-4820.

35. de Vries E, Boniol M, Dore JF, Coebergh JW, Eur J Cancer, 2004, 40, 1045-1052.

36. Danno K, Horio T, Photochem Photobiol, 1987, 45, 683-690.

37. Murphy G, Young AR, Wulf HC, Kulms D, Schwarz T, Exp Dermatol, 2001, 10, 155-160.

38. Trautinger F, Clin Exp Dermatol, 2001, 26, 573-577.

39. Chouinard N, Valerie K, Rouabhia M, Huot J, Biochem J, 2002, 365, 133-145.

40. Agar NS, Halliday GM, Barnetson RS, Ananthaswamy HN, Wheeler M, Jones AM, Proc Natl Acad Sci U S A, 2004, 101, 4954-4959.

41. Karakoula A, Evans MD, Podmore ID, Hutchinson PE, Lunec J, Cooke MS, J Immunol Methods, 2003, 277, 27-37.

42. Kowalczuk CI, Priestner MC, Pearson AJ, Saunders RD, Bouffler SD, Int J Radiat Biol, 2006, 82, 781-792.

43. Yang G, Zhang G, Pittelkow MR, Ramoni M, Tsao H, J Invest Dermatol, 2006, 126, 2490-2506.

44. Shindo Y, Hashimoto T, J Dermatol Sci, 1998, 17, 140-150.

45. Nishiyama Y, Yamamoto H, Allakhverdiev SI, Inaba M, Yokota A, Murata N, EMBO J, 2001, 20, 5587-5594.

46. Sander CS, Chang H, Hamm F, Elsner P, Thiele JJ, Int J Dermatol, 2004, 43, 326-335.

47. Smith ML, Chen IT, Zhan Q, O'Connor PM, Fornace AJ, Jr., Oncogene, 1995, 10, 1053-1059.

48. Kasai H, Mutat Res, 1997, 387, 147-163.

49. Kielbassa C, Roza L, Epe B, Carcinogenesis, 1997, 18, 811-816.

50. Kvam E, Tyrrell RM, Carcinogenesis, 1997, 18, 2379-2384.

51. Ichihashi M, Ueda M, Budiyanto A, Bito T, Oka M, Fukunaga M, Tsuru K, Horikawa T, Toxicology, 2003, 189, 21-39.

52. Woodcock A, Magnus IA, Br J Dermatol, 1976, 95, 459-468.

53. Godar DE, Photochem Photobiol, 1996, 63, 825-830.

54. Hirsch T, Marchetti P, Susin SA, Dallaporta B, Zamzami N, Marzo I, Geuskens M, Kroemer G, Oncogene, 1997, 15, 1573-1581.

55. Ono K, Kim SO, Han J, Mol Cell Biol, 2003, 23, 665-676.

56. Notingher I, sensors, 2007, 7, 1343-1358.

57. Gray GM, Yardley HJ, J Lipid Res, 1975, 16, 434-440.

58. Percot A, Lafleur M, Biophys J, 2001, 81, 2144-2153.

59. Jump DB, Crit Rev Clin Lab Sci, 2004, 41, 41-78.

60. Feingold KR, Adv Lipid Res, 1991, 24, 57-82.

61. Katsuta Y, Iida T, Inomata S, Denda M, J Invest Dermatol, 2005, 124, 1008-1013.

62. Jiang SJ, Chen JY, Lu ZF, Yao J, Che DF, Zhou XJ, J Dermatol Sci, 2006, 44, 29-36.

63. Wefers H, Melnik BC, Flur M, Bluhm C, Lehmann P, Plewig G, J Invest Dermatol, 1991, 96, 959-962.

64. Alessandrini F, Pfister S, Kremmer E, Gerber JK, Ring J, Behrendt H, J Invest Dermatol, 2004, 123, 1030-1036.

65. Haruta Y, Kato K, Yoshioka T, Biosci Biotechnol Biochem, 2008, 72, 2151-2157.

66. Ashley R, Andrea L, Rafael J, L HLH, The International Society for Optical Engineering, 2010, $756975692 Z-75691-75692 Z-75699$. 
67. Lampe MA, Burlingame AL, Whitney J, Williams ML, Brown BE, Roitman E, Elias PM, J Lipid Res, 1983, 24, 120-130.

68. Man MQ, Feingold KR, Elias PM, Arch Dermatol, 1993, 129, 728-738.

69. Takagi Y, Nakagawa H, Kondo H, Takema Y, Imokawa G, J Invest Dermatol, 2004, 123, 11021109.

70. Elias PM, Menon GK, Adv Lipid Res, 1991, 24, 1-26.

71. Menon GK, Feingold KR, Elias PM, J Invest Dermatol, 1992, 98, 279-289.

72. Merle C, Laugel C, Baillet-Guffroy A, Photochem Photobiol, 2010, 86, 553-562.

73. Ukpebor J, Llabjani V, Martin FL, Halsall CJ, Environ Toxicol Chem, 2011, 30, 632-639. 